\title{
Malignant Transformation of Liver Adenoma: An Analysis of the Literature
}

\author{
Olivier Farges Safi Dokmak \\ Department of Hepatobiliary and Pancreatic Surgery, Pôle des Maladies de l'Appareil Digestif, Hôpital Beaujon, \\ AP-HP, Université Paris 7, Paris, France
}

\section{Key Words}

Androgens · Fanconi's anemia • Focal nodular hyperplasia • Glycogen storage disease $\cdot$ Hepatic adenoma •

Hepatocellular carcinoma $\cdot$ Liver adenoma, malignant

transformation · Oral contraception

\begin{abstract}
As adenoma in other locations, hepatic adenoma (HA) may transform into hepatocellular carcinoma (HCC) and hepatocyte dysplasia is most probably the intermediate step between both conditions. Malignant HA may appear as microscopic or macroscopic areas of HCC within the HA. These areas are typically well differentiated and without vascular extension or satellite nodules. AFP measurements are not reliable as they are usually normal. The risk of malignant transformation of HA cannot be reliably quantified yet. Several series are concordant to show that approximately $5 \%$ of patients whose HA have been resected had pathological evidence of HCC within their HA. This figure however does not take into account fully transformed HA where evidence of the preexisting benign lesion might have disappeared. The risk of malignant transformation is correlated with the diameter of the HA and it is very unusual when it is $<5 \mathrm{~cm}$ and the same holds true for patients with multiple HA. These results suggest that small HA could be safely observed as they are also at low risk of bleeding. These conclusions might not ap-
\end{abstract}

ply to male patients who are at lower risk of HA, except in specific conditions, but appear to be at a much higher risk of malignant changes.

Copyright $\odot 2010$ S. Karger AG, Base

Hepatic adenoma (HA) and focal nodular hyperplasia (FNH) are the two most frequent benign liver tumors. For quite a long time they were considered close to each other both in pathology and radiology. For example in the 1960s, some textbooks considered both terms as synonyms. This of course has radically changed, but one has to admit that, much more recently, there has also been some confusion with the telangiectasic form of FNH that finally turned out to be a telangiectasic form of adenoma following molecular analysis [1].

FNH has a benign course in virtually all patients. As a matter of fact, it is not a tumor as there is no cell proliferation but a malformation which is polyclonal [2]. Because it has a hard consistency, it may compress intrahepatic biliary or vascular structures. However, there is no risk of bleeding or malignant transformation. Liver adenomas in contrast are genuine tumors and may therefore bleed or undergo malignant transformation, as adenomas in other locations. Both complications are the rationale for the resection of this tumor. Because hemorrhagic complications of adenoma are fully addressed in a pre- 
vious chapter [3], we will mainly focus on the risk of malignant transformation of HA into hepatocellular carcinoma (HCC).

\section{Evidence of Malignant Transformation of Liver Adenoma}

The potential of HA to transform into HCC was suggested 35 years ago when a mixed tumor composed of an $\mathrm{HA}$ and an HCC was described in a 21-year-old woman who had been on oral contraceptives (OC) for 2 years [4]. This observation was reminiscent of HCC associated with anabolic steroids but was not totally convincing as both tumors (HA and HCC) could have been coincident. The International Agency for Research on Cancer has indeed recently considered that there was sufficient evidence for the carcinogenicity of $\mathrm{OC}$ on liver cancer in populations that had a low prevalence of hepatitis $B$ viral infection and chronic liver disease [5]. Interestingly however, not all liver tumors associated with OC in these epidemiologic studies are HCC, some of them being cholangiocarcinoma.

Subsequently, other cases of HCC were reported in women known to have a preexisting HA [6]. Some however rightfully argued that it was impossible to rule out the possibility that the tumor was an HCC in the first place. It is indeed occasionally impossible to differentiate a very well differentiated HCC from an HA using imaging and conventional analysis of a liver biopsy. An intriguing observation of an $\mathrm{HCC}$ developing at the site of an OC-induced HA that had regressed when the OC was withdrawn [7] was worrying but did not help elucidate the issue. Although several authorities have pleaded for implementing international registries of biopsy-proven $\mathrm{HA}$ to determine their course, these were not set up as the general trend has been to remove all (large) HA.

Formal evidence of malignant transformation of HA has been provided by molecular analysis. The first of these is the demonstration that HA are monoclonal tumors (in contrast to FNH that are polyclonal) and consequently have an inherent risk of malignancy [2]. The second evidence is that a recurrent mutation described in another chapter [8] has been described in HA (the $\beta$ catenin mutation) which is common in HCC. Even more convincingly, $\beta$-catenin-mutated HA have an increased risk of undergoing malignant changes [9]. Carcinogenesis of HA has not been fully elucidated, but dysplasia is presumed to be the precursor lesion of HCC developing within adenoma as it is for HCC developing within regenerative nodules of cirrhotic livers.

Malignant Transformation of Liver

Adenoma

\section{Presentation of HCC within HA}

HCC within HA may present as discreet macroscopic nodules ranging from 1 to several centimeters, developing anywhere within the HA, and occasionally almost replacing it. Alternatively, microscopic areas of malignant transformation within HA have also been described [10]. These should be differentiated from cytological atypia that may, as for any other adenomatous lesions, be observed in HA.

HCC within HA are very predominantly well differentiated, AFP levels are usually normal and vascular extension or satellite nodules are rare. This of course might not be the case as the HCC progresses.

Although infrequently studied, transformation of HA does not usually result in particular morphological, radiological or biological features. Approximately half of totally benign $\mathrm{HA}$ are already symptomatic as a result of intratumoral bleeding or of abdominal pain or discomfort $[11,12]$. The proportion of patients with malignant HA who are symptomatic seems comparable. As transformed HA are usually large (as will be discussed below), imaging studies frequently show that they are heterogeneous, as are non-malignant HA of similar size [13].

\section{Risk of Malignant Transformation of HA}

\section{Malignancy within $H A$}

There is no observational study of patients with HA to determine the true risk of malignant transformation as the usual recommendation has been to remove HA. This risk can therefore only be estimated from the pathological records of operated patients. In surgical series of more than 20 patients [11, 12, 14-27], the proportion of HA with malignant transformation is $5 \%$ and this figure appears very reproducible over time (table 1). One has to realize that it is only a rough estimate of the risk of malignancy of HA for two reasons:

(1) Not all patients with an HA undergo surgery and the denominator (i.e. the number of patients at risk) is unknown. The current recommendation is indeed to remove HA $>4-5 \mathrm{~cm}[12,25,27]$, and smaller lesions are therefore excluded from these analyses. These smaller lesions appear to be at very low risk as the follow-up of small HA, or of patients whose multiple HA could not be entirely resected has not documented malignant transformation in recent series [12]. Another problem is that not all patients with large HA are identified. Approximately half of the patients with HA are asymptomatic

Dig Surg 2010;27:32-38 
Table 1. Incidence of malignant transformation of HA in surgical series of more than 20 patients stratified by decade of publication

\begin{tabular}{|c|c|c|c|c|c|}
\hline \multirow[t]{2}{*}{ Reference (first author) } & \multirow{2}{*}{$\begin{array}{l}\text { Publication } \\
\text { year }\end{array}$} & \multicolumn{3}{|c|}{ Patients with adenoma } & \multirow{2}{*}{$\begin{array}{l}\text { HCC within adenoma } \\
\text { number of patients }\end{array}$} \\
\hline & & total & resected & sex ratio & \\
\hline Kerlin [14] & 1983 & 23 & 17 & $21 / 2$ & 2 \\
\hline Mathieu [15] & 1986 & 27 & 27 & $27 / 0$ & 0 \\
\hline Leese [16] & 1988 & 24 & 17 & $16 / 8$ & 1 \\
\hline Total & & 74 & 61 & & $3(5 \%)$ \\
\hline Arrive [17] & 1994 & 29 & 21 & $27 / 2$ & $0^{1}$ \\
\hline Foster [18] & 1994 & 50 & 37 & NA & $1^{2}$ \\
\hline Nagorney [19] & 1995 & 24 & 19 & $22 / 2$ & 1 \\
\hline Weimann [20] & 1997 & 44 & 39 & $39 / 4$ & 2 \\
\hline Total & & 136 & 116 & & $4(4 \%)$ \\
\hline Ichikawa [21] & 2000 & 25 & 14 & $21 / 4$ & 2 \\
\hline Reddy [22] & 2001 & 25 & 25 & $25 / 0$ & 1 \\
\hline Terkivatan [23] & 2001 & 33 & 19 & $29 / 4$ & 0 \\
\hline Toso [24] & 2005 & 25 & 25 & $23 / 2$ & 2 \\
\hline Van der Windt [25] & 2006 & 48 & 16 & $48 / 0$ & 2 \\
\hline Cho $[26]$ & 2008 & 41 & 41 & $38 / 3$ & 2 \\
\hline Deneve [27] & 2009 & 124 & 119 & $116 / 8$ & 5 \\
\hline Bioulac-Sage [11] & 2009 & 128 & 128 & $116 / 12$ & 6 \\
\hline Dokmak [12] & 2009 & 122 & 122 & $108 / 14$ & 10 \\
\hline Total & & 530 & 509 & & $30(6 \%)$ \\
\hline
\end{tabular}

${ }^{1}$ Dysplasia was present in 3 patients. ${ }^{2}$ Hepatocholangiocarcinoma.

with their adenoma being discovered by chance [11, 12]. One can therefore assume that an undefined but probably significant proportion of HA are not recognized. Finally, these series usually arise from tertiary referral centers where large or symptomatic HA are overrepresented.

(2) What is actually measured is not exactly the risk of malignant transformation but the proportion of patients who have features of HCC within their HA. However, as the malignant component progresses, the underlying adenoma is likely to become hardly identifiable. Such tumors may therefore have been considered as pure HCC and excluded from series of HA patients. Another approach is therefore to try and identify among HCC patients those whose tumor could result from the transformation of an HA.

\section{HCC on 'Normal' Livers}

HCC develop in $75-80 \%$ of the patients on a background of liver cirrhosis and the most frequent etiologies are alcohol consumption and hepatitis $\mathrm{B}$ or $\mathrm{C}$ viral infection. HA in this context may occur but is fortuitous and cirrhotic nodules (not the HA) is the source of HCC. HCC without cirrhosis may occur: (1) in some of the same settings as those resulting in $\mathrm{HCC}$ associated with cirrhosis and this is particularly true in patients with hepatitis B infection or alcohol abuse, (2) as a result of conditions that infrequently lead to cirrhosis such as $\alpha_{1}$-antitrypsin deficiency or hemochromatosis, or (3) in the context of other etiologies that do not result in cirrhosis such as glycogen storage disease or hormones [28]. Only the third group includes etiologies that are known risk factors for $\mathrm{HA}$, but it has been considered to account for a minority of HCC.

This conclusion, however, deserves two comments:

(1) Epidemiologic data and in particular previous history of OC consumption (the most frequent cause of HA) have in fact not been precisely analyzed in HCC patients without cirrhosis. A striking feature, however, is that 
these patients are younger and more frequently females than those with significant fibrosis or cirrhosis. For example (and only looking at French studies), Bralet et al. [29] found that the mean age was 44 years and the male/ female sex ratio was 0.9 in HCC patients with no fibrosis as compared to 54 years and 3.4 in those with minimal portal fibrosis. Bege et al. [30] similarly found that HCC patients with no fibrosis were 10 years younger than those with mild or moderate fibrosis ( 57 vs. 66 years) and that males were not as predominant (sex ratio of 2). In comparison, HCC in cirrhotic patients peaks at the age of 70 years and men are at least 4 times more frequently affected than women [31].

(2) Most patients who have an HCC without cirrhosis do not clearly fall within one of these three groups of etiologies. It has in particular recently been realized that the metabolic syndrome is an increasing cause of HCC and in particular accounts for some of the HCC previously considered to develop on cryptogenic cirrhosis. However, only one third of the patients who have an HCC associated with a metabolic syndrome actually have cirrhosis, while the remaining two thirds have fibrosis of lesser extent (absent or mild) and approximately $40 \%$ have steatosis greater than $30 \%$ [32]. Furthermore, our group has recently shown that among 20 patients (all men) with HCC associated with a metabolic syndrome without significant fibrosis, 5 had evidence of a preexisting HA [32]. This observation suggests that the metabolic syndrome may also be a risk factor for HA in men and that the transformation of these HA could account for a previously unrecognized proportion of HCC.

\section{Malignant Transformation within Known Specific Etiologic Contexts}

\section{Oral Contraception}

The most classical risk factor for HCA is prolonged use of $\mathrm{OC}$, and it is therefore not surprising that most previously reported cases of malignant transformation have occurred in this setting. It is usually considered that the incidence of HA is 3-4/100,000/year when OC have been used for more than 2 years and more than 10 times less $(1-3 / 1,000,000 /$ year) when used for less than 2 years [33]. However, these estimations were performed in the 1970 s and actual figures taking into account the lower hormonal dosage of second- or third-generation OC are lacking. In three recent large European series, prevalence of OC consumption for more than 2 years in women with HA ranged between 85 and 95\% [11, 12,25], and in two thirds of them, OC had been used for more than 10 years [12]. There is little information on the carcinogenesis associated with OC, but one study quoted that it took 5 years to develop an HA, 8 years to see dysplasia within the HA, and 10 years to develop an HCC [34]. Withdrawal of OC is usually associated with a decrease in the diameter of $\mathrm{HA}$, but this is inconsistent and does not preclude malignant transformation. Updated information is obviously required, but these figures are consistent with the fact that women with HCC within their HA are usually in their 30s. Very few malignant HA have been described after the age of 50 and in our own series, the single woman in this case actually had only taken an OC very transiently, 25 years earlier [unpubl. data]. It is therefore doubtful that $\mathrm{OC}$ was the etiology in this patients as it has recently been underlined that regression of HA associated with OC is a slow but constant feature [11].

\section{Fanconi's Anemia and Androgens}

A second group of etiologies of HA include Fanconi's anemia and androgen treatments. Fanconi's anemia is an autosomal recessive disorder resulting in congenital abnormalities, aplastic anemia and a greater risk of developing specific neoplasms including HCC. Most cases of HCC have been observed in patients who had received androgen which is the reference treatment when no stem cell donors are identified. Evidence that HCC in these patients results from the transformation of an $\mathrm{HA}$ is that androgen treatments can induce HA and that some patients simultaneously had both adenomas and HCC within their liver. A particular feature is that HA (and HCC) associated with Fanconi's anemia tend to be multiple. An important aspect is also that as androgen treatments for Fanconi's anemia are initiated at a young age and as the main duration of treatment prior to HA/HCC development is 4 years, these patients develop their tumors at a median of 14 years. It has been estimated that the cumulative risk of having developed a liver tumor by the age of 50 years is $46 \%$ [35].

Androgen treatments have also been associated with HA and HCC in other settings than Fanconi's anemia, including other cause of anemia (such as paroxysmal nocturnal hemoglobinuria), endocrine substitutive treatments and bodybuilders [36]. The risk is correlated with the duration and dosage of androgen treatment. Most androgens belong to the $17 \alpha$-alkylated derivatives administered orally (although HA/HCC have also been described following the parenteral route). As for OC, other primary liver tumors may also appear including cholangiocarcinoma. The incidence of HCC associated with androgen 
treatments is not known. In a literature review of $230 \mathrm{pa}-$ tients with hepatic tumors associated with androgen treatments, $37 \%$ were $\mathrm{HA}, 52 \%$ were $\mathrm{HCC}$ and the remaining $11 \%$ had other etiologies. Only 6 patients had both HA and HCC, either simultaneously or sequentially [36].

Overall, men tend to be more frequently affected than women by the risk of liver tumors which is readily explained when androgens are used for endocrine reasons or by bodybuilders. This is however also the case for hematologic disorders, whereas these diseases do not occur more frequently in men than women. As for OC, HA may regress after androgen withdrawal. However, continued morphological monitoring of their livers is required as tumors may develop more than 20 years after discontinuation.

\section{Glycogen Storage Disease}

Glycogen storage disease (GSD) type I, and to a much lower extent type III, is a third classical etiology of HA (or more precisely of multiple HA) in which HCC has also occasionally been reported. As for most other etiologies, the presence of HCC is assumed (but not proven) to be the consequence of malignant transformation of an HA. However, there is no case of HCC associated with GSD without the simultaneous presence of HA. The largest series of HCC in this context includes a limited number (10 at most) of patients $[37,38]$. Owing to the rarity of this condition, the risk of malignant transformation is unknown. In a single institution analysis of 27 patients with type I GSD, 14 had HA, but no HCC was documented [39]. Likewise, a recent multi-institutional European survey on 288 patients with GSD type I showed that the overall prevalence of HA was $16 \%$, equal between males and females and was age dependent, being above $50 \%$ after the age of 24 [40]. In none of the 44 patients with HA however was there any case of HCC. On the other side, two large French series of HA have recently been published, that together cull 257 patients $[11,12]$. Of these, 6 (2\%) had glycogenosis (type I) including 1 patient with HCC among multiple HA. Taken together, these results indicate that the risk of malignant transformation of HA in the context of GSD is real, but probably low. Age at the time of identification of HCC ranges between 40 and 50, and as the life-span of GSD patients has increased with nutritional support, their numbers is likely to increase. An interesting observation is that most cases of HCC have been described in males (rather than in females) in a proportion that is not predicted by the gender distribution of GSD patients or even GSD patients with HA. As will be discussed below, the risk of malignant changes may therefore be higher in men.

Metabolic control has not been proven to reduce the risk of malignant transformation, although it has recently been underlined that most patients with HCC were poorly compliant to their treatments [38]. Current guidelines recommend ultrasound and AFP measurements every 3 months when HA are present and CT scan or MRI in case of growth or transition towards poorly defined margins. One should be aware that GSD may be associated with focal areas of steatosis that may be mistaken for HA. The reliability of this strategy has however not been evaluated and the sensitivity of AFP is low, as for HCC in general.

Liver resection in the context of GSD deserves a word of caution [41]. It is associated with an increased risk of severe postoperative complications and in particular of bleeding due to defects in platelet aggregation which can occur in up to $23 \%$ of the patients. Increased postoperative lactic acid levels are also common, whereas profound hypoglycemia is not, provided patients are hydrated with high dextrose intravenous fluids with strict monitoring of blood glucose (and lactic acid levels).

\section{Risk Factors for Malignant Transformation}

\section{Size of $H A$}

Size of HA is a risk factor for malignant transformation irrespective of etiology. Although the information is infrequently provided in the medical literature, all single $\mathrm{HA}$ with malignant changes were $>6 \mathrm{~cm}$ with one exception of a 4-cm HA that had no distinct nodule of HCC on gross findings but multifocal malignant degeneration on histology [10]. In fact, besides this case, the median diameter of the HA was $12 \mathrm{~cm}$. One of course cannot rule out that HCC might have completely replaced the HA in some patients with HA of smaller size. This, however, seems unlikely as small HCC in women most often develop on a background of cirrhosis or hepatitis B/C infection. In our institution, 18 out of 89 resected HCC in women were $\leq 6 \mathrm{~cm}$. Of these, a single patient had a $5-\mathrm{cm}$ HCC and no clear background liver disease except for an isolated anti-HBc serology [unpubl. data].

\section{Multiple HA}

Multiple HA as previously mentioned occur in particular in patients with glycogenosis or androgen treatments. Most patients, however, do not have these conditions and the reason why HA are multiple is unclear. Ap- 
proximately half of these patients have a limited number of HA (from 2 to 10) and the other half have the so-called polyadenomatosis entity [42] defined by the presence of more than $10 \mathrm{HA}$, scattered throughout the liver. In a recent analysis of our patients with HA, the risk of malignant changes was not influenced by the number of HA. It was $11 \%$ in patients with single lesions, $7 \%$ in those with multiple HA and 3\% in those with polyadenomatosis [12].

\section{Phenotype/Genotype}

Phenotype/genotype of the HA has recently been identified as an accurate predictor of malignant changes. This is particularly so in the presence of $\beta$-catenin mutation and this point is addressed in a distinct chapter [8].

\section{Gender}

HA are mainly observed in women with a sex ratio of $8-10 / 1$. HCC in contrast is predominantly a disease of men. The reasons for higher rates of HCC in males may relate to sex-specific differences in exposure to risk factors (viral infection, alcohol drinking, iron stores). However, there is experimental and clinical evidence that an- drogens independently influence HCC progression. This would explain the male predominance among malignant HA observed in the context of GSD or Fanconi's anemia. Additional studies are required to assess whether the same holds true in other settings.

\section{Conclusions}

Malignant transformation of HA is proven and currently estimated to occur in $5 \%$ of the patients. This figure varies, however, according to size, gender and phenotype/genotype of the HA. Routine molecular analysis of biopsy specimens may help in the future identify those patients at particular increased risk. In the mean time, women whose $\mathrm{HA}$ are $<5 \mathrm{~cm}$ and are related to OC could be observed following withdrawal of estrogens. Although $\mathrm{HA}$ are much less frequent in men, there is some evidence in the literature that these patients should be regarded at a much higher risk of HCC and should therefore be managed more aggressively.

\section{References}

$>1$ Bioulac-Sage P, Rebouissou S, Sa Cunha A, Jeannot E, Lepreux S, Blanc JF, et al: Clinical, morphologic, and molecular features defining so-called telangiectatic focal nodular hyperplasias of the liver. Gastroenterology 2005;128:1211-1218.

$>2$ Paradis V, Laurent A, Flejou JF, Vidaud M, Bedossa P: Evidence for the polyclonal nature of focal nodular hyperplasia of the liver by the study of X-chromosome inactivation. Hepatology 1997;26:891-895.

3 Huurman VAL, Schaapherder AFM: Management of ruptured hepatocellular adenoma. Dig Surg 2010 (in press).

$\checkmark 4$ Davis M, Portmann B, Searle M, Wright R, Williams R: Histological evidence of carcinoma in a hepatic tumour associated with oral contraceptives. Br Med J 1975;4:496498.

5 World Health Organization International Agency for Research on Cancer (IARC): Monographs on the Evaluation of Carcinogenic Risks to Humans, vol 91: Combined Estrogen-Progestogen Contraceptives and Combined Estrogen-Progestogen Menopausal Therapy. Lyon, IARC, 2007, pp 95103 [available at http://monographs.iarc.fr/ ENG/Monographs/vol91/mono91.pdf].

6 Larson KA, Weber SM, Fong Y, Blumgart LH: Malignant transformation of hepatic adenoma with recurrence after resection. HPB (Oxford) 2002;4:139-143.
7 Gordon SC, Reddy KR, Livingstone AS, Jeffers LJ, Schiff ER: Resolution of a contraceptive-steroid-induced hepatic adenoma with subsequent evolution into hepatocellular carcinoma. Ann Intern Med 1986;105:547549.

$>8$ Bioulac-Sage P, Balabaud C, Zucman-Rossi J: Subtype classification of hepatocellular adenoma. Dig Surg 2010;27:39-45.

$\checkmark 9$ Zucman-Rossi J, Jeannot E, Tran Van Nhieu J, Scoazec JY, Guettier C, Rebouissou S, Bacq $\mathrm{Y}$, et al: Genotype-phenotype correlation in hepatocellular adenoma: new classification and relationship with HCC. Hepatology 2006;43:515-524.

10 Micchelli ST, Vivekanandan P, Boitnott JK, Pawlik TM, Choti MA, Torbenson M: Malignant transformation of hepatic adenomas. Mod Pathol 2008;21:491-497.

11 Bioulac-Sage P, Laumonier H, Couchy G, Le Bail B, Sa Cunha A, Rullier A, Laurent C, Blanc JF, Cubel G, Trillaud H, Zucman-Rossi J, Balabaud C, Saric J: Hepatocellular adenoma management and phenotypic classification: the Bordeaux experience. Hepatology 2009;50:481-489.

12 Dokmak S, Paradis V, Vilgrain V, Sauvanet A, Farges O, Valla D, Bedossa P, Belghiti J: A single-center surgical experience of 122 patients with single and multiple hepatocellular adenomas. Gastroenterology 2009;137: 1698-1705.
13 Kogure T, Ueno Y, Sekiguchi S, Ishida K, Igarashi T, Wakui Y, Iwasaki T, Shimosegawa T: Liver cell adenoma showing sequential alteration of radiological findings suggestive of well-differentiated hepatocellular carcinoma. World J Gastroenterol 2009;15:12671272.

14 Kerlin P, Davis GL, McGill DB, Weiland LH, Adson MA, Sheedy PF 2nd: Hepatic adenoma and focal nodular hyperplasia: clinical, pathological and radiological features. Gastroenterology 1983;84:994-1002.

15 Mathieu D, Bruneton JN, Drouillard J, Pointreau CC, Vasile N: Hepatic adenomas and focal nodular hyperplasia: dynamic CT study. Radiology 1986;160:53-58.

16 Leese T, Farges O, Bismuth H: Liver cell adenomas. A 12-year surgical experience from a specialist hepatobiliary unit. Ann Surg 1988;208:558-564.

17 Arrive L, Flejou JF, Vilgrain V, Belghiti J, Najmark D, Zins M, Menu Y, Tubiana JM, et al: Hepatic adenoma: MR findings in 51 pathologically proved lesions. Radiology 1994;193:507-512.

18 Foster JH, Berman MM: The malignant transformation of liver cell adenomas. Arch Surg 1994;129:712-17.

19 Nagorney DM: Benign hepatic tumors: focal nodular hyperplasia and hepatocellular adenoma. World J Surg 1995;19:13-18. 
20 Weimann A, Ringe B, Klempnauer J, Lamesch P, et al: Benign liver tumors: differential diagnosis and indicators for surgery. World J Surg 1997;21:983-990.

-21 Ichikawa T, Federle MP, Grazioli L, Nalesnik M: Hepatocellular adenoma: multiphasic CT and histopathologic findings in 25 patients. Radiology 2000;214:861-868.

$>22$ Reddy KR, Kligerman S, Levi J, Livingstone A, et al: Benign and solid tumors of the liver: relationship to sex, age, size of tumors, and outcome. Am Surg 2001;67:173-178.

$\checkmark 23$ Terkivatan T, de Wilt JH, de Man RA, van Rijn RR, Zondervan PE, Tilanus HW, IJzermans JN: Indications and long-term outcome of treatment for benign hepatic tumors: a critical appraisal. Arch Surg 2001; 136:1033-1038.

-24 Toso C, Majno P, Andres A, Rubbia-Brandt L, Berney T, Buhler L, Morel P, Mentha G: Management of hepatocellular adenoma: solitary-uncomplicated, multiple and ruptured tumors. World J Gastroenterol 2005; 11:5691-5695.

25 Van der Windt DJ, Kok NFM, Hussain SM, Zondervan PE, Alwayn IPJ, de Man RA, Ijzermans JNM: Case-oriented approach to the management of hepatocellular adenoma. Br J Surg 2006;93:1495-1502.

-26 Cho SW, Marsh JW, Steel J, Holloway SE, Heckman JT, Ochoa ER, Geller DA, Gamblin TC: Surgical management of hepatocellular adenoma: take it or leave it? Ann Surg Oncol 2008;15:2795-2803.
7 Deneve JL, Pawlik TM, Cunningham S, Clary B, Reddy S, Scoggins CR, Martin RCG, d'Angelica M, et al: Liver cell adenoma: a multicenter analysis of risk factors for rupture and malignancy. Ann Surg Oncol 2009; 16:640-648.

28 Evert M, Dombrowski F: Hepatocellular carcinoma in the non-cirrhotic liver. Pathologe 2008;29:47-52.

29 Bralet MP, Regimbeau JM, Pineau P, Dubois S, Loas G, Degos F, Valla D, Belghiti J, et al: Hepatocellular carcinoma occurring in nonfibrotic liver: epidemiologic and histopathologic analysis of 80 French cases. Hepatology 2000;32:200-204.

30 Bege T, Le Treut YP, Hardwigsen J, Ananian P, Richa H, Campan P, Garcia S: Prognostic factors after resection for hepatocellular carcinoma in nonfibrotic or moderately fibrotic liver. A 116-case European series. J Gastrointest Surg 2007;11:619-625.

31 Borie F, Bouvier AM, Herrero A, Faivre J, Launoy G, Delafosse P, Velten M, Buemi A, et al: Treatment and prognosis of hepatocellular carcinoma: a population-based study in France. J Surg Oncol 2008;98:505-509.

32 Paradis V, Zalinski S, Chelbi E, Guedj N, Degos F, Vilgrain V, Bedossa P, Belghiti J: Hepatocellular carcinomas in patients with metabolic syndrome often develop without significant liver fibrosis: a pathological analysis. Hepatology 2009;49:851-859.

33 Rooks JB, Ory HW, Ishak KG, Strauss LT, Greenspan JR, Hill AP, Tyler CW Jr: Epidemiology of hepatocellular adenoma. The role of oral contraceptive use. JAMA 1979;242: 644-648.

34 Tao LC: Are oral contraceptive-associated liver cell adenomas premalignant? Acta Cytol 1992;36:338-344.
5 Alter BP: Cancer in Fanconi anemia, 19272001. Cancer 2003;97:425-440.

-36 Velasquez I, Alter BP: Androgens and liver tumors: Fanconi's anemia and non-Fanconi's conditions. Am J Hematol 2004;77:257267.

37 Talente GM, Coleman RA, Alter C, Baker L, Brown BI, Cannon RA, et al: Glycogen storage disease in adults. Ann Intern Med 1994; 120:218-226

38 Franco LM, Krishnamurthy V, Bali D, Weinstein DA, Arn P, Clary B, et al: Hepatocellular carcinoma in glycogen storage disease type Ia: a case series. J Inherit Metab Dis 2005;288:153-162.

39 Labrune P, Trioche P, Duvaltier I, Chevalier P, Odievre M: Hepatocellular adenomas in glycogen storage disease type I and III: a series of 43 patients and review of the literature. J Pediatr Gastroenterol Nutr 1997;24: 276-279.

40 Rake JP, Visser G, Labrune P, Leonard JV, Ullrich K, Smit PA: Glycogen storage disease type I: diagnosis, management, clinical course and outcome. Result of the European Study on Glycogen Storage Disease Type I (ESGSD I). Eur J Pediatr 2002;161:S20-S34.

41 Reddy SK, Kishnani PS, Sullivan JA, Koeberl DD, Desai DM, Skinner MA, Rice HE, Clary BM: Resection of hepatocellular adenoma in patients with glycogen storage disease type Ia. J Hepatol 2007;47:658-663.

42 Veteläinen R, Erdogan D, de Graaf W, ten Kate F, Jansen PLM, Gouma DJ, van Gulik TM: Liver adenomatosis: re-evaluation of aetiology and management. Liver Int 2008; 28:499-508. 